\title{
Functional Cartography - About the quality of maps from the era of artefacts to the era of services and beyond
}

\author{
Georg Gartner ${ }^{\mathrm{a}, ~ *}$ \\ ${ }^{a}$ Research Group Cartography, Department of Geodesy and Geoinformation, Vienna University of Technology, Erzherzog- \\ Johannplatz 1, A-1040 Vienna, Austria \\ georg.gartner@tuwien.ac.at \\ * Corresponding author
}

Keywords: functional cartography, quality, theoretical cartography

\begin{abstract}
:
Cartography as a discipline is generally concerned with communicating spatial information to human users (Kraak et al 2017). This is done through applying methods to communicate spatial information by visually perceivable graphical codes. This transfer is needed only because of the restricted human perception system (MacEachren 1995). The subsequently applied cartographic methods are generally sacrificing the quality, accuracy, homogeneity and integrity of the processed spatial data for the sake of human-perceivable aggregated and subsequently abstracted information. Usually this results in representation models, speaking of maps as the most common ones.
\end{abstract}

While the production of maps, including all methods dealing with transforming data into graphics such as generalisation, symbolisation have been heavily looked into in research traditionally, the way maps are used or can be used is recently gaining stronger interest, such as from cognitive and perception perspectives, dealing with questions such as "how maps work". However, it can be argued, that even if we know a lot about how maps can be produced and modelled, and how they work, we ultimately are not able to say if a map is "good" in terms of satisfying the needs and demands of a particular user in a particular situation and context, thus describing the concept of quality of maps (Gartner 1998).

A map can be designed in a way, that it it perceivable, has no graphic conflicts, communicates particular spatial information but might not be leading into the same satisfaction as another map depicting the same spatial information in a different way. We can think of this as similar to other communication forms, e.g. human communication. Although two persons might express something similar, differences in the words which are used, how they are used, how they are pronounced, how quick/slow/loud they are spoken, of whom they are expressed and in which situation are influencing, whether one or the other communication is more effective and successful and seen as the one with "higher quality" (Gartner 1998).

Maps have a variety of functions (Morrison 1978). It can be assumed, that only if the map fulfils those particular function, it is assessed and judged as a good map. But what are those functions? Some are related to the data and the information which is depicted in the map (how accurate, how complete), some are related to the way the data is visualised and graphically depicted (how perceivable, how clear) and some are related to the user and his context (how pleasing, how entertaining, how useful, how informative, how "enabling").

In this paper a structured analysis of the functions of maps due to the various context dimensions of the cartographic communication process will be given. It is argued, that cartography as a discipline is going through a major change of paradigms, the cartographic era of artefacts is replaced by the era of services while a cognitive era in the domain of cartography can be envisioned already (Griffin et al 2017). For all of those eras different functions and criterias of qualities need to applied.

\section{References}

Freitag U. (2008): Von der Physiographik zur kartographischen Kommunikation - 100 Jahre wissenschaftliche Kartographie. In: Kartographische Nachrichten 58, 2008/2. S.59-67.

Gartner G. (1998): About the quality of maps. In: Cartographic Perspectives, 30. http://dx.doi.org/10.14714/CP30.662

Griffin, A.L., White, T. , Fish, C., Tomio, B., Huang, H., Robbi Sluter, C., Meza Bravo, J.V., Fabrikant, S.I., Bleisch, S., Yamada, M., Picanço, Jr., P., Jr. (2017). Designing across map use contexts: A research Agenda. International Journal of Cartography, DOI: 10.1080/23729333.2017.1315988. 
Kraak, M.-J. and Fabrikant, S.I. (2017). Of Maps, Cartography, and the Geography of the International Cartographic Association. International Journal of Cartography, DOI: 10.1080/23729333.2017.1288535.

MacEachren, A.M. (1995) How maps work, Guilford Press, New York.

Morrison, J. (1978) "Towards a functional definition of the science of cartography with emphasis on map reading", The American Cartographer, 5, pp. $97-110$. 